\title{
The integration of music and its influence on the inclusion of autistic children in educational activities of preschool institutions
}

\author{
Shqipe Avdiu-Kryeziu* \\ Arsim Avdiu** \\ *“Kadri Zeka” University, Gjilan, Kosovo. ORCID ID: 0000-0001-9237-7187 e-Mail: Shqipea.k@ \\ hotmail.com \\ ** Corresponding Author, PhD. Cand, Primary School “Hasan Alia”, Vitia, Kosovo. ORCID ID: 0000- \\ 0001-8391-9810 e-Mail: arsim_avdiu89@hotmail.com
}

DOI 10.12975/rastmd.2021936 Submitted October 15, 2021 Accepted December 25, 2021

\begin{abstract}
This study aims to collect data on the approaches of music integration and its influence on the inclusion of autistic children in educational activities of preschool institutions- the Kosovo case. The study includes both: a summary of the research literature of this case, and research conducted using semistructured interviews with preschool teachers employed in preschool institutions in Gjilan-Kosovo. As a sample of this study, 6 head preschool teachers and 2 support teachers who work in preschool institutions of Gjilan. The instruments used in this research are semi-structured interviews and the results that most participants support the idea that the integration of music has an influence on the inclusion of autistic children in educational activities of preschool institutions. As the results of this study imply, teachers who work in preschool institutions can use music in educational activities with the aim of the successful inclusion of children with autism in the learning process.
\end{abstract}

\section{Keywords}

autism, music, inclusion, children, preschoolers

\section{Introduction}

In general, Kosovo has a shortage of preschool institutions which are usually located in cities only, resulting in challenges in the education system such as low inclusion of children in these institutions, in a special case, children with autism. Even though there is progress in this process and the inclusion of autistic children is not denied, there is a lack of sufficient areas and necessary conditions. (Aliu, 2015)

The educational and care process towards preschool children, by using different activities such as entertainment, cultural activities, creative activities, residence, nutrition, sports and physical activities, and music, represents the best way of child protection. During attendance of children in preschool institutions, these institutions must implement the principle of inclusion for all children. (UNICEF \& BE, 2018)

For the purpose of achieving a more effective social inclusion in 
these institutions, there should be given opportunities for children to approach their peers. Involvement of musical activities in weekly planning for preschoolers has potential for all children inclusion in daily activities and increases confidence in children to participate in such activities, including children with special needs, specifically autistic children. (Sze, 2021)

Autism is a developing disorder that is often introduced in the first three years of childhood. Diagnosing autism is not easy because there are no simple methods that can be used to surely say that any child has signs related to autism. The diagnosis relies on recognising certain forms of child behaviour. (UNICEF, 2018)

The aim of this research is to study more deeply if there are any methods or alternatives for the treatment and inclusion of autistic children in activities with other normal children. Considering that these autistic children are usually treated differently from other children, the focus of this study is to assist and make progress on autistic children inclusion in activities with other children. (Pelayo \& Sanchez, 2013)

The art of music is as old as humanity (Dhomi, 2010) and using music therapy in activities is done for individual purposes from education professionals who should be trained in this area of music therapy. Music therapy is used for raising the emotional, physical, cognitive, and social needs of autistic children. (Pelayo \& Sanchez, 2013)

During education activities with children, music can play an important role in children's inclusion, because many children with special needs need music therapy. To them, music neutralises negative feelings, increases tolerance level, harmonises inner peace, etc. (Sze, 2021)

The most highlighted difficulty in autistic children is language and communication development. Many researchers note that about $50 \%$ of autistic children cannot develop effective communication known as spoken language. From this point of view, we can say that we ought to find something that helps autistic children to communicate in preschool institutions, involving music as a part of daily activities with children. (Kulla, et al., 2014)

Autistic children have difficulties in social-emotional interaction and in behaviours, but they can change because no autistic individual shares the same features, they differ from each other while some of them achieve a development stage where they become independent, the others need support their whole life. Only $2 \%$ of autistic children are known for having talent in fields such as maths, music, and arts. (Kulla, et al., 2014)

The opportunities of using music in educational activities compared to music therapy have been of interest to researchers these last years. Data from these researches show an optimistic view of the overall inclusion of these groups in educational activities in preschool institutions. Supporting these activities between these groups, communication between children using songs as learning instruments has considerable gains to autistic children in the process of learning and memorising words. (Wiseman, 2015) 
We can say that all autistic children are the same, but they share the same main features such as difficulties in understanding spoken language, difficulties in expressing themselves, difficulties in pronunciation and low control of voice, weak understanding of social interactions, they show quick reactions towards touching, smelling, sounds, dancing with music, etc. (Trajkovski \& Vasilevska Petrovska, 2020)

From early childhood and since birth, human beings need to create social interactions, especially during the first 12 months of their lives. Outside stimulations from the environment are crucial, they foster brain development, formation of nerves, changes during growth, etc. Child development is an implication of social interaction in their early childhood in social environments, mainly from what is served to them in preschool institutions. (Archontopoulou \& Vaiouli, 2020)

It is hard to measure the impact of music therapy and music integration in educational activities, although Wiseman did an experiment where he measured four elements in a child's behaviour: voice and voiceless communication, eye contact, facial expressions, and noisy music communication. This research, as Wiseman mentioned, describes a raise in physical contact, eye contact, and a high level of emotional involvement. But the sample was not big enough, and more research needs to be done. (Wiseman, 2015)

Support teachers for children with special needs have used music in autistic children to change their spiritual state and examine their emotional problems.
Music shows an influence on the activities of children, they like to listen to music and to sing, and this helps them to fight stress. This study shows that music must be integrated not only in music classes but also in regular daily activities. Also, this study notes that music integration in literature helps children connect more with daily events and activities. (Sze, 2021)

Planned music activities in early childhood programmes are a method that promises an increase in child involvement in organised activities of preschool institutions, including children with autism. Music represents a natural experience in increasing the levels of children's abilities and encourages showing these individual abilities using different activities. (Archontopoulou \& Vaiouli, 2020)

Based on the study of Archontopoulou and Vaiouli (2020), music plays a crucial role in the everyday lives of children and especially in institutions where daily activities are planned, where children can communicate and interact with their peers in their early childhood stage. This study shows that music is the key element that encourages children to explore words to create important events in their lives, to make friends, and to connect with their family members. (Archontopoulou \& Vaiouli, 2020)

Moreover, German researcher Wiseman (2015) has a similar thought with the one mentioned above about musical integration in autistic children's activities, saying that integrated music in activities tackles three fields: communication, socialisation, and behaviourism. Based on this study, 
using music does not require being qualified for this, because this task can be performed by each education professional. (Wiseman, 2015)

Music is an instrument in every child's promotion and inclusion, including autistic children in early childhood. There are different perceptions and challenges of educators on using music in activities with preschoolers (0-6 years old), where studies show that in general, preschool teachers do not have much knowledge and information about the use of music as an educational tool in early childhood, and often they feel uncertain in using music in daily activities regardless of the field. (Archontopoulou \& Vaiouli, 2020)

According to Sharda (2018), evidence shows that musical integrationinteraction in educational activities has shown positive effects on ASD (autistic) children, in emotional engagement, social interactions, communication, children-parents relationships, peers relationship, suggesting that musical activities can lead to measurable changes in autistic children. This study has shown strong peaks in music integration in activities with autistic children such as extended musical abilities, improved memory, socialisation, more effective response, etc, describing deeper effects that music has caused to autistic children. (Sharda, et al., 2018)

From the strengths of using music in children's activities, we should consider the needs of each and every child, offering them a communicative way that can benefit them, depending on the challenges they face such as: in expressing words, offering emotional support, increasing motivation, easing movement, rehabilitation, etc. (Pelayo \& Sanchez, 2013)

In general, studies show that autistic children can be responsible and can perform equal to their peers, thus suggesting that by music autistic children can be considered almost equally developed to their peers. (Wiseman, 2015)

According to the researcher Fole (2017), who conducted research with 3-6 years old children that were exposed to activities through music, the data concluded that music can be used as an educational tool in communicating with autistic children and children with disabilities/special needs. (Fole, 2017)

Learning efficiency plays a critical role in offering qualitative learning and the implementation of the new practices in educational activities. The teacher must be aware of his didactic role in the teaching experience and according to the researchers Archontopoulou \& Vaiouli (2020, they aimed in studying these perceptions of teachers of the period of early childhood and using music as a tool for promoting social and emotional development of the preschool autistic children in an inclusive environment with all children. This study concludes that music strategies implemented in educational activities with autistic children in inclusive groups promoted the social and emotional development of these autistic children. (Archontopoulou \& Vaiouli, 2020)

It is hard to measure the effect of music as a specific intrusion on autistic children but much research has shown 
that music can treat some difficulties of autism such as social interaction, communication, emotional reaction, and also imagination. These findings of autistic children can be further studied and researched. (Wiseman, 2015)

\section{The problem of the study}

This study aims to research the influence of music integration in the inclusion of autistic children in educational activities in preschool institutions-applied in Kosovo.

To conduct more precise research and to see the importance of music integration in educational activities in preschool institutions, we have based our research on this research question:

How does music integration in preschool institutions influence autistic children's inclusion?

\section{Methodology}

To achieve the aims of this research and to seek more concrete answers to research questions, we used the qualitative method of research that aimed at researching the life experiences of humans in their environments. In many cases, these two are combined in order to achieve the disclosure of the circumstances cause-consequence. The origin of qualitative research is in descriptive analysis and is specifically an inductive process (logically, from special situations in a logical conclusion). (Kumar, 2017)

\section{Participants}

To conduct this research, as a sample of research we took preschool teachers/ educators that are currently employed in preschool institutions of Gjilan in Kosovo.
From the data gathered from preschool teachers of preschool institutions using semi-structured interviews, we came to the conclusion that the use of music in educational activities in children groups of all ages, in preschool institutions has positive effects on the inclusion of autistic children.

Research data were gathered using semi-structured interviews conducted with the help of 8 preschool teachers of public preschool institutions of Gjilan municipality, from them 2 support preschool teachers (who work with children with special needs). The questions of the interviews were the same for all teachers.

The sample of the research was taken from the teachers who work in preschool institutions of Gjilan, inclusive institutions. The sample is intentional in these institutions where autistic children are present.

The interviewed preschool teachers work with children of age groups 2-3 years old, 3-4 years old, 4-5 years old, and 5-6 years old, the same groups including children with special needs and autistic children. While, the 2 support teachers are temporarily employed in teaching children with special needs, and almost every academic year they have autistic children in their classrooms.

All participants/preschool teachers are graduates, from them 2 are MA graduates and have 5-15 years of job experience.

The preschool institutions where the research is conducted are located in the urban zone inside the municipality of Gjilan, divided into groups: two full- 
time teachers and one support teacher.

To use a more confidential interview, the interview teachers were coded with initials:

A (preschool teachers that teach groups age 3-4 years old)

$B$ (preschool teachers that teach groups age 4-5 years old)

C (preschool teachers that teach groups age 5-6 years old)

D (support preschool teachers that teach with all groups 2-6 years old)

\section{Research instruments}

As an instrument to gather data we have chosen the semi-structured interview which contains five questions (see appendix 1).

The semi-structured interview is used to gather data in a wide range of research types. It is usually used to gather socialqualitative data, when the researcher is interested in the experiences, behaviours, and comprehension of humans, and why they experience and comprehend the social world in this way. (Matthews \& Ross, 2010) During the research, you are free to request whatever you need, and based on the format that suits your situation. (Kumar, 2017)

To draw more concrete and reliable results, the data from the interviews were analysed in a written form. Then, the data were anonymously used for all the interviewed teachers.

\section{Results and discussions}

The interview conducted with teachers of preschool education focused on these issues:

- Music integration and its influence in the inclusion of autistic children in educational activities of preschool institutions

- The opportunity to integrate music in all fields of educational activities

The implementation of educational activities in preschool institutions is built through games and other creative activities.

From the interviews of teachers, we came to the conclusion that in all preschool institutions of the municipality of Gjilan autistic children's inclusion is present, in which there is at least one autistic child part of these institutions. Moreover, in the interview teachers agreed that music has an influence on the inclusion of autistic children and they considered music as a great educational tool. The interviewed teachers agreed that in all fields of educational activities they used music for all children, especially for those with autism since music had a tremendous impact on their inclusion in these activities because they loved music.

Music integration as a tool in children inclusion, including those autistic children in their early childhood, is very important in their social inclusion. In general, research shows that integrated music in educational activities in preschool institutions has a huge influence. (Archontopoulou \& Vaiouli, 2020) 
Music integration in educational activities and inclusion of autistic children

On the question addressed to the preschool teachers: During educational activities in preschool education, do you use music? Music is part of many activities that are realised in preschool institutions, because here we use games that foster creativity, and this is closely related to music. Furthermore, all children love music, and this helps us a lot in using activities and including children that love music in these activities. All the interviewed teachers had a similar thought on this question. (Teachers A, B, C, D)

On the next question, Can we use music in all developmental fields of activities? Preschool teachers had different thoughts and shared different perspectives on music. Music can be used in all developmental fields of activities, and make the process of realisation of these activities easier and more creative, more available, more comfortable, and more acceptable for children, etc. (Teachers A, B)

Even though other teachers think that music sometimes interferes them in activities because children get concentrated on the music and can't hear their teachers speak, they want to listen and play music and no longer see as a priority, children love music and enjoy the process of learning when teachers use music in these activities regardless the field of the activity. (Teachers $\mathrm{C}$ )

Support teachers think that music fits all groups of children, all children want to incorporate music in their educational activities, and it is more adaptable to involve children in games and activities through music. (Teachers D)

On the next question: Does music integration influence autistic children's inclusion in educational activities in preschool institutions? These answers were provided: we have a long work experience in inclusive education, approximately $10-15$ years, and autistic children inclusion in educational activities is a challenge in itself because they need continued concentration from the teacher. Regarding music integration, it has a huge impact on the inclusion of autistic children. (Teachers A, B, C). While the support teachers which are more included in the process of inclusion because their primary job priority is inclusive education, agree on the thought that music is an effective and important educational tool in autistic children's inclusion, but often time depends on the level of the skills of children or in which field the child is more skilful to adapt inside the educational group. (Teachers D)

In which development field does music have more impact during integration in educational activities of autistic children? Regarding this question, teachers provided these answers: music has more influence on languages and communication because while children sing, they use words and imitate others. (Teachers A) According to us, children while using music in different activities they develop their psychomotor skills, they dance with music, play, jump, and imitate. (Teachers B) Children develop skills from music and they all want to be part of activities where music is present, but mostly music has an impact on the development of language 
and communication fields, in arts, physical development, in life and work fields, almost in every development field. (Teachers C) The impact of music is general, autistic children love music and we think that music has an impact in all fields such as language and communication, in arts, maths (especially when they learn numbers, symbols, and figures while singing), natural sciences (when they learn about water, air, aggregate states), in social and environmental sciences, physical education, sports and health, life and work. (Teachers D)

Music integration in educational activities provides children, especially autistic children, a more disciplined learning process, and a safer work environment. They develop the fields of language and communication, emotions, comprehension, physical education, etc. (Eren, 2015)

On the question: Do all autistic children love music? All teachers responded that they all love music, but sometimes it depends on their daily mood and other outside factors such as the weather, emotional state, environment, etc. (Teachers A, B, C, D)

Music integration in activities promotes a positive environment, it is beneficial for children, especially children with autism. (Meyer, 2017)

Regarding the question: In which part of the activity do you integrate music more? We integrate music more in the developmental part of the activity (Teachers A), music can be integrated into all parts of the activity, depending on the planned daily topic for the activity
(Teachers B, C). Music can be integrated into all parts of the activity starting from the introduction, body, and conclusion. But there are also different thoughts of teachers, for example, one of the teachers thinks that music is best to be integrated into the introduction part of the activity because it has a direct impact on autistic children. (Teachers D)

\section{Conclusion}

Based on the results from the research through interviews with teachers of preschool institutions about music integration and its impact in the inclusion of autistic children in educational activities in preschool institutions, all interviewed preschool teachers agree that they use music as an educational tool for activities.

Music must be part of educational activities and must be used as a tool for inclusion. Children with special needs (autism) gain from music integration in the development of these skills: socialism, communication, behaviourism, physical health, etc. (Fole, 2017)

They use music in all developmental fields, once in all parts of the activity, and also agree that music impacts all developmental fields of children such as language and communication, physical education, social-emotional, etc.

About music integration and its influence in the inclusion of autistic children in educational activities in preschool institutions, interviewed teachers agree that it has a huge influence on the inclusion of autistic children as a result of music integration in educational activities. 
Limitations of the study

The research is mainly based on the researched literature and the interviews conducted with teachers that work in preschool institutions of the municipality of Gjilan. Variables of the study are based on semi-structured interviews. If any other instrument would be applied for the research of this issue, we could get other results and other conclusions.

\section{Acknowledgements}

Grateful to all those who contributed to the realisation of this research. A special thanks to the interviewed teachers that participated in this research, and our research became complete. 


\section{Biodata of Authors}

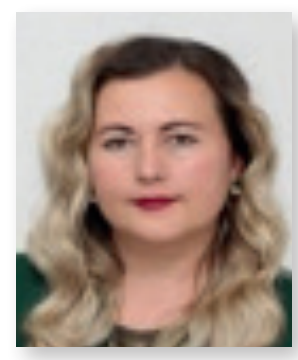

\section{Shqipe Avdiu-Kryeziu}

Doctor of Science in Education, Master of Inclusive Education, Master of Pedagogy, Faculty of Education. I am interested in topics: education, inclusion, interculturalism, evaluation in education, etc. Affilation: "Kadri Zeka" University, Gjilan, Kosovo. e-Mail: Shqipea.k@hotmail.com ORCID: 0000-0001-9237-7187

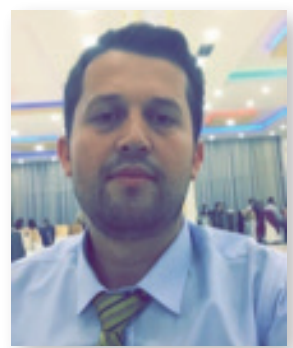

\section{Phd, Cand. Arsim Avdiu}

He has received a bachelor degree in education from the University of Prishtina in Prishtina, Kosovo (2012), a master degree in Pedagogy from the Public University of Tetovo in Tetovo, North Macedonia (2015). He is almost in the end of his PhD studies in Education at University St. Clement of Ohrid in Bitola, North Macedonia. He works as a full-time teacher at the primary school "Hasan Alia" in Vitia, Kosovo since 2014. From 2017 to 2019 he was the trainer of the new Kosovo curriculum. He published several scientific articles in scientific journals and also participated in several national and international conferences. Affilation: Primary School “Hasan Alia”, Vitia, Kosovo. e-Mail: arsim_avdiu89@ hotmail.com ORCID: 0000-0001-8391-9810 


\section{References}

Aliu, L., 2015. Analysis of the education system in Kosovo. Prishtina: FriedrichEbert-Stiftung.

Archontopoulou, A. \& Vaiouli, P., 2020. Music and Social Skills for Young Children with Autism: A Survey of Early Childhood Educators. International Journal of Educational Research Review, pp. 190207.

Dhomi, A., 2010. From the note to the song. Prishtina: University of Prishtina Faculty of Education.

Eren, B., 2015. The Use of Music Interventions to Improve Social Skills in Adolescents with Autism Spectrum Disorders in Integrated Group Music Therapy Sessions. Procedia - Social and Behavioral Sciences, p. 207 - 213.

Fole, S. V., 2017. Music Education and Its Impact on Students with Special Needs. Scholarship and Engagement in Education, 1(1), pp. 1-7.

Kulla, F., Remaçka. L., \& Ndrio. M., 2014. I am among you, different, different, equal.... Tirana: World Vision.

Kumar, R., 2017. Research methodology. Prishtina: USAID \& MASHT.

Matthews. B. \& Ross, L., 2010. Research methods. Tirana: CDE.

Meyer, J., 2017. Music Education with Autistic Students, Music Education with Autistic Students in the Mainstream Elementary Classroom. Toronto: Department of Curriculum, Teaching and Learning Ontario Institute for Studies in
Education of the University of Toronto.

Pelayo, J. M. G. \& Sanchez, C. S., 2013. Music Therapy with Autistic Children: A Multiple Case Study. Angeles: Systems Plus College Foundation.

Sharda, M. et al., 2018. Music improves social communication and auditorymotor connectivity in children with autism. Translational Psychiatry, pp. 2-13.

Sze, S., 2021. Educational Benefits of Music in an Inclusive Classroom. Cypriot Journal of Educational Sciences, 1(16), pp. 251-265.

Trajkovski, V. E. \& Vasilevska Petrovska, I., 2020. Supporting Social Skills and Positive Parenting: A Handbook for Parents of Children with Autism Spectrum Disorders and Professionals from Their Support Environment. Skopje: Macedonian Scientific Association for Autism.

U. \& B., 2018. Inclusion of children with disabilities in preschool education, Skopje: UNICEF.

UNICEF, 2018. What is autism and how can we support children with autism? Skopje: Resources center for parents of children with disabilities.

Wiseman, S., 2015. The use of music as an educational intervention for children with autistic spectrum disorder (ASD). Research in Teacher Education. 5(1), pp. 7-14. 


\section{Appendix 1-The interview from}

Dear teachers,

I am Shqipe Avdiu-Kryeziu, a researcher of education sciences. The questionnaire that I am asking you to fill in is about music integration and its influence in the inclusion of autistic children in educational activities in preschool institutions - applied in Kosovo. The data will remain confidential and will be used only for educational purposes.

Thank you!

Name:

Age:

Education:

Institution you work in:

URBAN ZONE

Teaching experience:

With which group ages do you work:

Group age 3-4 years old

Group age 4-5 years old

Group age $5-6$ years old

Support teachers

During activities with preschoolers, do you use music?

Can music be used in all developmental fields of activities?

Does music integration impact the inclusion of autistic children in educational activities in preschool institutions?

In which developmental field does music influence more autistic children during educational activities?

Do all autistic children love music?

In which part of the activity do you integrate music more? 